\title{
Wheat Varieties Resistance to the Biotic Stresses Generated by Diseases - Main Factor of Agro Ecological Economy
}

\author{
Vasile Marius CĂRĂBĂȚ ${ }^{1}$, Mihai BERCA ${ }^{1}$, Roxana HOROIAȘ ${ }^{1 *}$, Cristian Florinel CIOINEAG ${ }^{2}$ \\ ${ }^{1}$ Faculty of Management, Economic Engineering in Agriculture and Rural Development. University of \\ Agronomic Science and Veterinary Medicine, 59 Marasti Blvd., Bucharest, Romania \\ ${ }^{2}$ Faculty of Agriculture. University of Agronomic Science and Veterinary Medicine, 59 Marasti Blvd., \\ Bucharest, Romania \\ *Corresponding author: roxana.horoias@gmail.com
}

Bulletin USAMV series Agriculture 72(2)/2015

Print ISSN 1843-5246; Electronic ISSN 1843-5386

DOI 10.15835/buasvmcn-agr: 11432

\begin{abstract}
For wheat crop, in 2013-2014 a comeback of resistant strains of extremely harmful diseases such as yellow rust (Puccinia striiformis) and fusarium (Fusarium spp.) was observed. By preventing the absorption of solar energy and limiting the yield, by average, with $30-40 \%$ for the untreated pesticide version, entropy in wheat increased significantly. Entropy increase was also supported by the necessity to double the number of treatments from 1-2, to 3-4 in this special years. Currently there are no plant protection products that can control the wheat pathogens $100 \%$. Thermodynamic biosystem reconstruction can be achieved only by obtaining and using resistant or immune varieties to the whole complex of wheat diseases. In the wheat crops in Romania, we can meet at least 13 diseases that, together or separately, may cause 15\% damages even under treatment, taking into account the phenomena of resistance. Entropy on the food chain plant - animal - human or directly plant - human can also be increased by induction of mycotoxins (DON) in useful productions, which are extremely dangerous for food safety. All these have significant economical and environmental negative effects.
\end{abstract}

Keywords: disease, entropy, Fusarium spp., Puccinia striiformis, resistance.

\section{INTRODUCTION}

Plant protection is as necessary to the agricultural ecosystem as medical prophylaxis of humans. Sheldrake (1995) argues that disease resistance formation is not only a consequence of genetic mutations, but also a cause of the change in the morphic fields of those fungi. Breeders have not created, so far, varieties fully resistant to diseases (Berca, 2014). Damage from diseases, pests and weeds can reach $20-50 \%$, out of which $15 \%$ are caused by diseases. Without treatments, the damages of wheat crop reach $1500-3000 \mathrm{~kg} / \mathrm{ha}$, the variation being given by biotic factors that influence the diseases. The aim was to see in what extent the diseases can form resistance to treatment (Popov and Barbulescu, 2007). Resistance occurs mainly in the ear and is accompanied by an unacceptably high formation and accumulation of mycotoxins in grains (van Harmelen, 2002). Such a situation is threatening the quantity but especially the quality of the crop, the animal and human health.

\section{AIMS AND OBJECTIVES}

The study aims to demonstrate that a high tolerance of the varieties is not a very lasting one. Diseases begin quickly enough to become resistant at their turn, so that in 10 years the evaluation marks move to the right by $2-3$ points, which means that the fungicide treatments are still very necessary, with all the disadvantages of the entropy increasing induction.

\section{MATERIALS AND METHODS}

Experiences were installed in the experimental field from Modelu (Calarasi) and the natural 
resistance of different very new wheat varieties was monitored. Experiments were mounted in blocks of 4 repetitions in order to perform statistical calculations. The frequency (\%), the intensity (1-9 grades) and the degree of attack for fusarium (Fusarium spp.) and yellow rust (Puccinia striiformis) were determined in the field. Untreated plots were left in order to estimate the effect of treatments, for comparisons. Correlation calculations were performed for the evaluation marks and the yields, the extent in which the diseases affect the yield was identified and the entropy evolution was measured.

\section{RESULTS AND DISCUSSION}

Centralization of the results led to the finding that in normal treatments, without registering resistance phenomena, crop losses are limited to $15 \%$ of variety potential. The losses rise to $20-25 \%$ in terms of resistance installation on treatment and to $40-50 \%$ plus mycotoxins (800$1000 \mathrm{mg} / \mathrm{kg}$ ) for no treatment. Entropy calculation indicates an increase with $22-30 \%$ compared to a normal situation. Useful biomass and yield quality decrease. It is noted that the energy phenomena are profoundly distorted in their evolution as soon as the plant lack of resistance towards the main diseases is installed (Fig. 1).

Increases of the attack expressed numerically by evaluation marks (1-9) lead to the following findings:

a) Entropy increase by $10 \%$ for grades 1 and 2, which can't be found in a significant decrease

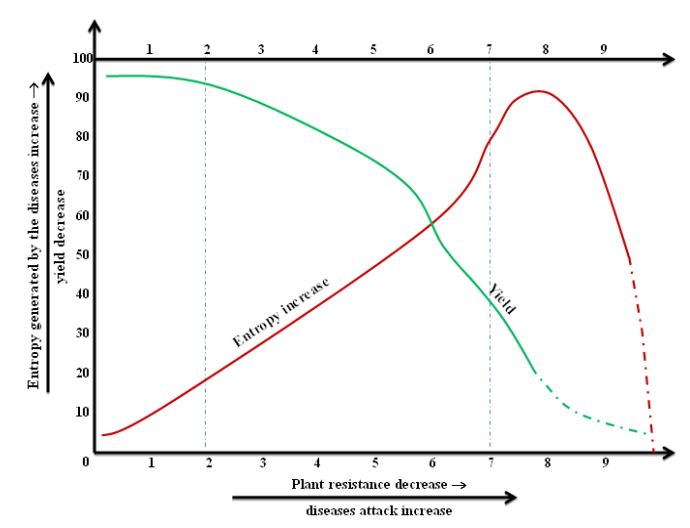

Fig. 1. Correlation between the entropy increase, generated by the diseases, and the useful biomass decrease to a very wide range of wheat varieties (original) in the yield - positive side, shows that the entropies are not harmful.

b) At 3-7 the harvest decrease is linear, with $\approx 10 \%$ for each point of evaluation.

c) For 7-9, increases the entropy caused by the disease to $>70 \%$ and the yield is collapsing.

Intersection of entropy and yield occurs near note 6 , after which diseases should not be allowed to grow. Since the yield decline don't reflect the magnitude of the increasing entropy, it is necessary to seek a correction way of. Such a way may be an indicator:

$$
I_{m}=\frac{P}{M}
$$

where:

$\mathrm{I}_{\mathrm{m}}=$ mixed index ( 0 to 10 ); $\mathrm{P}=$ actual production, expressed in subunit (0-1) to maximum production; $\mathrm{M}=$ mycotoxin content, relative to the maximum allowed/100.

\section{CONCLUSION}

The emergence of resistance to fusarium and rust, and other diseases create significant disadvantages for breeders. Production and crop quality are reduced on average by $15-20 \%$ for medium resistance and 50\% for total resistance. Installing genetic disease resistance leads to the suppression of chemical treatments, to regulation of the energy relations between plants and the environment, to the optimization of the quantum activity of photosynthesis, to the reduction of the entropy in the system and its upcoming to bioeconomy. The economic effects are significant, up to 700 euro/ha, as well as the environmental impact, of its resources and of human and animal food safety.

\section{REFERENCES}

1. Berca M. (2014). Probleme privind bolile la grau. Simpozion al Societatii Nationale de Protectia Plantelor

2. Popov C. and Barbulescu A. (2007). 50 de ani de activitate stiintifica in domeniul protectiei culturilor de camp impotriva bolilor si daunatorilor. INCDA Fundulea Annals, Vol. LXXV, 371-404

3. Sheldrake R. (1995). A New Scrience of Life: The Hypothesis of Morphic Resonance. Park Street Press, ISBN: 0892815353

4. van Harmelen M. (2002). Mycotoxins in the Cereal Chain. Concerted Action EU Project PL98-4094, http://www. plant.wageningen-ur.nl/projects/fusarium/. 